\title{
The Historical Contribution of Amateurs to the Study of Double Stars
}

\section{P. Couteau}

Observatoire de Nice, B.P. 139, F-06003 Nice, France

Double stars are favourite objects for amateurs, who can see them with modest instruments and easily observe their eventual motion. Moreover, it is possible to calculate their orbits, and even masses, with no other equipment than a pencil, a piece of thread and two pins to draw the ellipses that these systems have been following for centuries.

Binary stars are part of those classes of objects whose geometrical structure remains the same at different scales, they are internally homothetic ${ }^{1}$ and represent a field to which fractal geometry may be applied. All this explains the popularity of these objects with amateurs: anyone is able to see some of them, whatever the power of their instruments.

For a long time astronomers were amateurs, it is only comparatively recently that they have become professionals, when administrative structures arose to regulate the profession. Men have devoted their fortunes, their lives, and their comfort, to the study of the heavens and of the laws of nature: Galileo (1564-1642) is a very good example.

William Herschel (1738-1822) was the first to draw attention to double stars as being able to demonstrate Keplerian motion. His fundamental paper on this dates from 1803, and he cites nine systems of which the orbital motion was definite.

William Herschel was not an astronomer by profession, he was a musician and organist at the Chapel Royal at Bath. He was not fettered by research, unlike the astronomers by profession who were busy with cartography concerned with the form of the Earth and with navigation. He was given a comfortable pension by King George III after his discovery of Uranus in 1781; that pension allowed him to construct his telescopes, which were by far the most powerful and advanced for that period.

In $1821 \mathrm{~W}$. Herschel published two catalogues of double stars, with a total of 812 systems, many of which had been discovered by his predecessors and in particular, by Christian Mayer (1779). The way for his successors was mapped out. One of these was to be William Herschel's own son, John (1792-1871), who discovered more than five thousand double stars from the Cape and London, with telescopes built by the family.

\footnotetext{
1 Homothetic: such that for a given set of curves, a line through any point intersects all the curves of the set at the same angle - Eds.
} 
Russia was not long in becoming famous for its astronomical research thanks to Wilhelm Struve (1783-1864), who was given the task of constructing the imperial observatory near St Petersburg. Astronomers from the neighbouring Germany, such as Olbers, Gauss, Encke, Humboldt and Bessel helped with their advice. The largest refractor in the world, the $24-\mathrm{cm}$ equatorial, built by the famous firm of Fraunhofer at Munich, was ready for service at Dorpat in 1824 .

What happened was what Sir James South described as "the golden harvest of double stars from the fields of heaven". In three years, this instrument had enabled more than 1600 objects to be discovered, and in $1837 \mathrm{~W}$. Struve published the famous Dorpat catalogue, which contained ten thousand measurements of three thousand pairs, a model of its kind that remained for about a century the bible of doublestar observers. Later, in 1843, father and son built the fine observatory of Pulkova, near St Petersburg, with a $38-\mathrm{cm}$ refractor. This observatory and the instruments it contained remained the most modern and the most powerful in the world until the 1860 s, when the United States of America vigorously threw itself into the race to have the largest refractor, under the driving influence of enlightened amateurs.

Before coming to this race for large telescopes, which was to be of great benefit to the study of double stars, we must speak about two outstanding men: William Rutter Dawes (1799-1868) in Britain and Baron Ercole Dembowski (1812-1881) in Italy.

The Reverend W.R. Dawes was a medical practitioner and clergyman; his taste for astronomical observation dates from 1826, when he examined the double-star catalogues of Sir William Herschel. In 1829 he acquired a Dollond equatorial of just under 4 inches, and he made 600 measurements, which made a great impression on everyone, and he was named "the eagle-eyed". In 1853 he came into contact with Alvan Clark, who was to become the manufacturer of the largest American objectives. Clark had difficulties in starting as an optician and he sent Dawes a list of double stars, really celestial jewels, that he had discovered with small objectives that he had made. Dawes ordered three objectives of 7, 7.5 and 8.25 inches, with which he was to make some startling discoveries, whilst all the time ministering to bodies and souls, and also despite his health, which rarely left him free from trouble.

In 1850 he discovered the Crêpe Ring of Saturn, independently discovered the same year by W.C. Bond with the new 15-inch refractor at Harvard. He also produced some remarkable drawings of Mars, and saw markings on Ganymede and Callisto. He made his own micrometers, and devised ingenious diaphragms to improve this or that observation. It was he who discovered the equation giving the resolving power of an objective. Finally, he also discovered some real celestial jewels, one of which Dawes $1=$ ADS 13946 is now one of the most interesting in the sky. The separation between the components is now 0.10 arcsec and is continuing to decrease from its value of 0.60 arcsec in Dawes' time.

Dawes measured almost all the objects in the Dorpat catalogue, and his measurements are of astonishing accuracy, which, having been made more than a century ago, are of the highest value for the calculation of orbits. This observer measured objects to $40 \%$ of the resolving power, with angular errors that did not amount to more than a few degrees. He was the link between the Struves and the new generation that America was about to foster. 
Baron Ercole Dembowski, the son of a Polish general who served under Napoleon, lived most of his life in Italy. He was a sailor in the Austro-Hungarian service, but it would appear that the long nights at sea and the spectacle of the heavens awoke in him the wish to devote himself to the study of those distant spheres. He bought a $135-\mathrm{mm}$ dialyte refractor and installed it at Cremano near Naples. Six years later he acquired a Merz 162-mm refractor and moved to Gallarate, near Lake Como, where he had an observation tower built adjoining his villa.

E. Dembowski was to make a total of 21000 measurements over 30 years, of which 18000 were from Gallarate. He was one of the most assiduous observers of double stars, and the most prolific of his time.

Dembowski, like Dawes a few years before, undertook the measurement of the stars in the Dorpat catalogue with a precision equal to that of Dawes. But then another amateur, perhaps the most remarkable of the three, Sherburne Wesley Burnham (1838-1921) began his remarkable discoveries, at Chicago, close to the Dearborn Observatory. This was in 1873; Burnham had only a 6 -inch $(15-\mathrm{cm})$ telescope, the objective was perfect, but he had neither a drive nor a micrometer. So it was Dembowski who measured the pairs discovered by Burnham, whose contribution was soon to provide a decisive spur in the drive for large telescopes.

Dembowski and Burnham worked eight thousand kilometres apart, but their observations complemented one another. Burnham was to show his gratitude to Dembowski in dedicating his famous catalogue of 1290 double stars to him in 1900.

Until 1873 the Dorpat catalogue $(\Sigma)$, augmented by the Pulkova one (O $\Sigma$ ) formed the definitive work for known doubles. Those of John Herschel were neglected as being too wide, or else situated in the southern hemisphere. Those two catalogues provide evidence for the motion in a large number of binaries, which encourages observers. W.R. Dawes and E. Dembowski guaranteed continuity in the middle of the 19th century, and they showed that the observation of double stars is more a question of the person involved than one of equipment. The selection has been carried out, because thanks to them pairs with orbital motion have been detected, and numerous orbits are becoming visible.

In 1838 a man was born in Thetford, a small town in New England, thanks to whom, whilst never an astronomer by profession, the study of double stars was to develop into one of the major disciplines by the beginning of the 20th century: this was Sherburne Wesley Burnham. It was he who steered the drive towards the larger telescopes that revolutionized the observation of double stars.

Burnham was, by profession, an official court reporter at Chicago. He was highly regarded in his job and became a member of the Board of Administration of the Chicago and Northern Pacific Railway. His attention to astronomy was drawn by reading a copy of Burrit's Geography of the Heavens. His home was right next door to the old Dearborn Observatory, where the famous 18.5-inch Clark, the largest refractor in the world, had just been installed. Burnham was a frequent visitor to the establishment's library and became friendly with Alvan Clark, from whom he ordered a 6-inch refractor at a cost of eight hundred dollars. The telescope was delivered in 1873. In four years, Burnham was to discover 451 binaries, many of which are notable, among them $\beta$ Delphini, with a period of 26 years. 
It caused a revolution in the rather rigid world of double stars. The "golden harvest" had not been exhausted, indeed a young enthusiast, with a very modestsized instrument had shown the contrary. And this young amateur was discovering binaries with his small refractor, whilst the fine Dearborn equatorial, the largest in the world, a few hundred metres away, had hardly been used since the terrible fire of 9th October 1871, that national catastrophe that had razed a large part of Chicago.

The press took up the cause, funds were acquired and Burnham was named Acting Director of the observatory, without a salary. He is the only amateur to be named director of a major observatory. He revitalized the establishment and went on to discover 413 new pairs there, before resigning his post because his job proved so absorbing. His friend, G.W. Hough succeeded him. But Burnham had become an important figure in American astronomy; it was his advice that decided the site of the Lick Observatory, where he stayed for four years, whilst his wife and six children lived at San José at the foot of the mountain. After the installation of the great Yerkes refractor, near Chicago, Burnham was granted its use over the week-ends, whilst for the rest of the week he was in his office at the courts.

He still found time to assemble a general catalogue of all doubles, a marvel of its kind, with full references for every object, the number of which is over 13000 .

Apart from all this, Burnham also encouraged pupils, who themselves were to become great professionals: W.J. Hussey (1866-1926) and R.G. Aitken (18641951). They were also to reap a rich harvest, but that is indeed another story.

In Europe, amateurs also achieved remarkable success. There was a whole series of them in Britain, where the drive for giant instruments was carried further by Newall, who, with his large $63-\mathrm{mm}$ refractor dethroned the Dearborn telescope from first place, then handed on the laurels to Lord Rosse, who constructed his great 1.8 -m reflector.

Double stars have made a few European amateurs famous, the first that we shall mention being Camille Flammarion (1842-1924). In 1868 he was the first to publish a list of pairs where orbital motion had been confirmed, and which at that time numbered eighteen. Flammarion, by his various publications, and his enthusiasm, where his romantic view sometimes gained the upper hand over the constraints of scientific rigour, contributed enormously - as did Arago - to the popularization of astronomy and the encouragement of people to take it up as a vocation.

Three other names are pre-eminent as regards double stars: R. Jonckheere (1889-1974), the Reverend T.E. Espin (1858-1934) and Dr Paul Baize, who is still working in his native Normandy.

Robert Jonckheere had a private observatory built at Hem, near Lille. His 33$\mathrm{cm}$ refractor enabled him to discover 1000 pairs at a time when Aitken was carrying out his great searches; a number that he later increased to 3300. The Reverend Espin used reflectors, and around the 1920s discovered about 3000 binaries under English skies, which obviously are not always foggy. But the Jonckheere and Espin pairs have components that are too widely separated to be dynamically interesting, but their searches are remarkable for the number of objects that they discovered.

Dr Paul Baize, born in 1901, is the prototype amateur, who is both an observer and binary-star theoretician. The son of a doctor, his father naturally steered him 
towards a medical career, a career that has been very full, because apart from being a consultant paediatrician, he also served at the Hospice des Enfants-Assistés, as lecturer at the School of Paediatric Nursing, and as a school doctor, which was more than enough to occupy a single person. But that was not enough for Dr Baize. In 1925 he acquired a $108-\mathrm{mm}$ refractor, then he had the use of the equatorials at the Paris Observatory, one a $30.5-\mathrm{cm}$ and then a $38-\mathrm{cm}$. The total number of measurements made by Dr Baize is 24044 , and he is among the top ten "measurers" in the history of double stars.

The study of double stars has often been considered as of marginal interest for professional astronomers working in fundamental astronomy, and later in the development of astrophysical methods, and later still in cosmology. It was Burnham who started professionals studying binaries after the great Lick refractor was brought into service. But they have never been numerous, and it has been amateurs who have ensured continuity.

Nowadays, modern interferometric methods require complicated physics and information technology that are out of the reach of amateurs. But they are the ones who will have to observe the numerous slow-moving pairs that will only reveal their orbit much later in the future. The giant refractors are gradually being retired from scientific use; would it not be a good idea for amateurs to form groups and make arrangements to keep them maintained, as has already started to be done in certain organisations?

Then, thanks to the efforts of those who love the heavens, orbits will abound, and thanks to the Hipparchos satellite, which will provide the parallaxes, knowledge of stellar evolution will be the final beneficiary.

\section{Bibliography - Limited to Fundamental Works}

Aitken, R.G., New General Catalogue of Double Stars, Vols I \& II, Carnegie Institute, Washington D.C., 1938: 17180 pairs with measurements and references

Burnham, S.W., A General Catalogue of Double Stars, Parts I \& II, Carnegie Institute, Washington D.C., 1906: 13665 pairs with measurements and references

Dawes, W.R., his observations are gathered together in Mem. Roy. astron. Soc., 5 (1833), 8 (1836), 19 (1851) and 35 (1867)

Dembowski, E., Misure Micrometriche de Stella Doppie e Multiple, 2 Vols, Reale Academia Lincei, $1883 \& 1884$

Herschel, Sir J.F.W., "A Catalogue of 10300 Multiple and Double Stars", Mem. Roy. astron. Soc., 40 1874); covers the discoveries made by both the Herschels father and son, but is just an index and contains no epochs or measurements

Jeffers, H.M., van den Bos, W.H. \& Greeby, F.M., Index Catalogue of Visual Double Stars, 1961: list of more than 60000 pairs from pole to pole

Jonckheere, R., Catalogue and measures of Double Stars, Mem. Roy. astron. Soc., 51, 1916

Schiaparelli, G.V., Misure di Stella Doppie, 2 Vols, Brera, Milan, 1888

Struve, F.G.W., Stellarum duplicum et multiplicum mensurae micrometricae, Dorpat Observatory, 1837: the famous Dorpat catalogue 